\title{
Relação mulheres e natureza nos interstícios da Educação
}

\section{Ambiental}

\author{
Relaciones mujeres y naturaleza en los intersticios de la Educación
}

Ambiental

Relationship between women and nature in the interstices of

Environmental Education

\author{
Juliana Corrêa Pereira Schlee ${ }^{1}$ \\ Dárcia Amaro Ávila ${ }^{2}$ \\ Paula Corrêa Henning ${ }^{3}$
}

\begin{abstract}
Resumo
Como educadoras-pesquisadoras ambientais assumimos um compromisso ético e político, nos provocando a pensar sobre o campo de saber da Educação Ambiental como uma possiblidade de criarmos outras formas de pensar e problematizar verdades e certezas que atravessam a relação das mulheres com a natureza, que tomam como natural na seara da Educação Ambiental. Para alcançar o objetivo proposto nesta pesquisa vamos percorrer alguns acontecimentos discursivos que entrelaçam mulheres e natureza, através das teorizações de Michel Foucault entendemos que os acontecimentos discursivos são eventos importantes, traçados históricos que são tomados como discursos, assim pinçamos da história a Primeira Conferência das Nações Unidas sobre o Meio Ambiente Humano (Estocolmo, 1972); a Conferência Intergovernamental sobre Educação Ambiental (Tbilisi, 1977), que destacam a relação do homem para solução dos problemas ambientais pautados na racionalidade científica e os eventos da Conferência das Nações Unidas sobre Desenvolvimento e Meio Ambiente (Rio de Janeiro, 1992) e a IV Conferência das Nações Unidas sobre a Mulher (Pequim, 1995) que posiciona as mulheres em destaque, convocando-as para proteção e cuidado do planeta. Nessa direção, utilizamos as contribuições de estudos de gênero e meio ambiente a fim de mostrar o quanto estes modos de pensar, valorizar e conceituar a relação mulheres e natureza vem se constituindo e se modificando pela história e cultura. Além disso, visibilizar as aproximações com a educação ambiental nos possibilita problematizarmos e (re)inventarmos novos modos de nos relacionar com a natureza na atualidade.
\end{abstract}

Palavras-Chave: Acontecimentos; Educação Ambiental; Gênero; Mulheres; Natureza.

\section{Resumen}

Como educadoras-investigadoras ambientales asumimos un compromiso ético y político, provocándonos a pensar sobre el campo de saber de la Educación Ambiental como una posibilidad de crear otras formas de pensar y problematizar verdades y certezas que atravesan la relación de las mujeres con la naturaleza, que toman como natural en la mina de la Educación Ambiental. Para alcanzar el objetivo propuesto en esta

\footnotetext{
${ }^{1}$ Mestranda do Programa de Educação Ambiental pela Universidade Federal do Rio Grande - FURG/CAPES. Integrante do Grupo de Estudos em Educação, Cultura, Ambiente e Filosofia - GEECAF/ FURG, Rio Grande, Rio Grande do Sul, Brasil, julianaschlee @ gmail.com.

${ }^{2}$ Doutoranda do Programa de Educação Ambiental (PPGEA, FURG) e participante dos grupos de pesquisa Sexualidade e Escola e Grupo de Estudos em Educação, Cultura, Ambiente e Filosofia - GEECAF/FURG, Rio Grande, Rio Grande do Sul, Brasil, darciaamaroavila@gmail.com.

${ }^{3}$ Doutora em Educação, Professora dos Programas de Pós-graduação em Educação e Ciência e Educação Ambiental da Universidade Federal do Rio Grande, Rio Grande, Rio Grande do Sul, Brasil, paula.c.henning@gmail.com.
} 
investigación vamos a recorrer algunos acontecimientos discursivos que entrelazan mujeres y naturaleza, a través de las teorizaciones de Michel Foucault entendemos que los acontecimientos discursivos son eventos importantes, trazados históricos que son tomados como discursos, así sacamos de la historia la Primera Conferencia de las Naciones Unidas sobre el Medio Ambiente Humano (Estocolmo, 1972); la Conferencia Intergubernamental sobre Educación Ambiental (Tbilisi, 1977), que destacan la relación del hombre para solución de los problemas ambientales pautados en la racionalidad científica y los eventos de la Conferencia de las Naciones Unidas sobre Desarrollo y Medio Ambiente (Rio de Janeiro, 1992) y la IV Conferencia de las Naciones Unidas sobre la Mujer (Pequín, 1995) que posiciona a las mujeres en destaque, convocándolas para la protección y cuidado del planeta. En esa dirección, utilizamos las contribuciones de estudios de género y medio ambiente a fin de mostrar lo cuanto estos modos de pensar, valorar y conceptuar la relación mujeres y naturaleza viene constituyéndose y modificándose por la historia y cultura. Además, visibilizar las aproximaciones con la educación ambiental nos posibilita problematizar y (re)inventar nuevos modos de relacionarnos con la naturaleza en la actualidad.

Palabras claves: Acontecimientos; Educación Ambiental; Género; Mujeres; Naturaleza.

\begin{abstract}
In this research we seek to problematize and think how the relationships between women and nature constitute the interstices of Environmental Education. In order to reach the objective proposed in this research we will go through some discursive events that interweave women and nature, through theorizations of Michel Foucault we understand that discursive events are important events, historical tracings that are taken as speeches, therefore we pinch from history the First United Nations Conference on the Human Environment (Stockholm, 1972); the Intergovernmental Conference on Environmental Education (Tbilisi, 1977), which highlight the relationship of man to the solution of environmental problems based on scientific rationality and the events of the United Nations Conference on Development and Environment (Rio de Janeiro, 1992) and IV United Nations Conference on Women (Beijing, 1995) which places women in the spotlight, summoning them for protection and care of the planet. What interests us here is not to highlight right and wrong in our relations with nature, but to highlight the historical and cultural constructions that make up this relationship. This way, we use the contributions of gender and environment studies in order to show how these ways of thinking, valuing and conceptualizing the relationship between women and nature is becoming and is being changed by history and culture. Besides that, visualizing approaches to environmental education enables us to problematize and (re) invent new ways of relating to nature nowadays.
\end{abstract}

Keywords: Events; Environmental Education; Gender; Women; Nature.

\title{
1. Introdução e ferramentas metodológicas
}

A filosofia nos faz pensar em como nos constituímos como mulheres e homens ao longo das nossas vidas e através de práticas sociais e culturais num processo que não é linear, harmônico, finalizado ou completo. Nesta perspectiva, tendo como intercessor desta pesquisa o filósofo Michel Foucault, para pensarmos e problematizarmos o campo de saber da Educação Ambiental, buscamos alguns autores e autoras que se dedicam a tensionar algumas verdades estabelecidas nessa seara educacional. Assim pesquisadores como Isabel Carvalho (2012), Leandro Guimarães (2008), Marcos Reigota (2014), Paula Henning (2012) nos auxiliam a desnaturalizar olhares e saberes sobre as relações da sociedade e natureza que muitas vezes são tomados como naturais e verdadeiros. Além desses estudiosos/as, algumas autoras como Mary Castro e Miriam Abromovay (2005), Sandra Garcia (1992) nos ajudam na compreensão das relações entre mulheres/natureza. 
Para pensar sobre as mulheres e sua relação com a natureza e a Educação Ambiental, é importante pensar na construção histórica, social e cultural em que posiciona sujeitos femininos e masculinos, tendo a história e a cultura como importantes elementos para esta construção. Nesta pesquisa nos propomos a utilizar o conceito de Gênero como uma ferramenta teórica e política para problematizar os processos que instituem modos de ser mulheres e que sustentam desigualdades e diferenças sociais, culturais e discursivamente construídas. Tais diferenças, atravessadas por relações de poder, são produzidas, vividas e legitimadas (MEYER, 2004), assim como nas relações com a natureza na seara da Educação Ambiental.

Para alcançar o objetivo proposto nesta pesquisa vamos percorrer alguns acontecimentos discursivos que entrelaçam Mulheres, Educação Ambiental e natureza. Entendendo que os acontecimentos discursivos são eventos importantes, traçados históricos que são tomados como discursos, como algo que irrompe num certo tempo e lugar. Foucault explica:

Se os discursos devem ser tratados, antes, como conjuntos de acontecimentos discursivos, que estatuto convém dar a esta noção de acontecimento que foi tão raramente levada em consideração pelos filósofos? Certamente o acontecimento não é nem substância nem acidente, nem qualidade, nem processo; o acontecimento não é da ordem dos corpos. Entretanto, ele não é imaterial, é sempre no âmbito da materialidade que ele se efetiva, que é efeito, ele possui seu lugar e consiste na relação, coexistência, dispersão, recorte, acumulação, seleção de elementos materiais; não é o ato nem a propriedade de um corpo; produz-se como efeito de e em uma dispersão material (FOUCAULT, 2014, p. 54).

O modo de constituir-se como mulheres e como natureza é atravessado pelos discursos, enunciações e acontecimentos que modelam, controlam e regulam e são regulados por nós, sujeitos desse tempo. Partindo dessa premissa, buscamos a Educação Ambiental, como campo de saber importante e potente para a análise do mundo contemporâneo em seu processo de construção. Através de uma perspectiva pós-estruturalista, problematizamos verdades e certezas que atravessam a constituição das mulheres e sua relação com a natureza e a Educação Ambiental.

\section{Nos interstícios da Educação Ambiental}

Enquanto pesquisadoras educadoras-ambientais nos propomos a olhar para os fundamentos históricos e filosóficos da Educação Ambiental, na dimensão das relações da humanidade com a natureza, e assim buscamos pensar e problematizar a relação mulheres e natureza nos interstícios da Educação Ambiental. Neste contexto, entendemos a Educação 
Ambiental como um ato político, como a análise das relações políticas, econômicas, sociais e culturais entre a humanidade e a natureza e as relações entre os seres humanos (REIGOTA, 2014). Em uma articulação ética e política, nos provocamos a pensar sobre o campo de saber da Educação Ambiental como uma possiblidade de criarmos outras formas de pensar e talvez seja necessário reinventar práticas efetivas de experimentação e maneiras de ser no contexto social, mental e ambiental (HENNING, 2012). Para isso, entendemos que há muitas formas de ver as relações das mulheres com a natureza no âmbito ambiental, constituindo nossas maneiras de ser e de se comportar diante da natureza, assim muitas questões foram levantas por diferentes autoras:

Será que todas as mulheres do mundo se preocupavam "naturalmente" com o estado do meio ambiente acima de outros problemas que encaram diariamente? São as mulheres vítimas especiais da destruição do seu meio ambiente?(BRAIDOTTI et al, 1994, p.27-29).

Qual é a especificidade da relação entre mulher e meio ambiente? Ela é distinta da relação homem/meio ambiente? (GARCIA, 1992, p. 163).

Tais questões trazidas por Braidotti et al (1994) e Garcia (1992) nos fazem pensar nos modos como nos constituímos como natureza e como mulher. Tais interrogações nos potencializam a pensar o quanto esses discursos são fabricados na cultura que, atrelados por relações de poder, fazem emergir verdades e saberes, dados como naturais. No entanto, esta relação mulheres/natureza tem sido alvo de muitas divergências e antagonismos: se por um lado as mulheres são vistas com laços especiais com a natureza, como salvadoras naturais da natureza, por outro lado reconhecem que as mulheres e a natureza são simultaneamente subjugadas, de formas históricas e culturais específicas (BRAIDOTTI et al, 1994).

Atualmente, além da desconstrução da categoria mulher, é problematizada a relação das mulheres com a natureza e o meio ambiente. Neste contexto, mulheres e meio ambiente não podem ser naturalizados e homogeneizados, tampouco sua relações universalizadas (ÁVILA, RIBEIRO E HENNING, 2016). Nos interstícios da educação ambiental formas de se relacionar com a natureza, com o mundo vão se constituindo histórica e culturalmente.

Preocupamo-nos aqui de não fazer inversões, trazendo à tona as mulheres como conhecedoras privilegiadas e potenciais salvadoras da natureza, mantendo as hierarquias e perpetuando o dualismo mulher/homem. A sua posição como mulheres não as qualifica para gerir o ambiente melhor do que qualquer outra pessoa, mesmo que a população das mulheres seja a mais afetada pela degradação e pela crise ambiental (BRAIDOTTI et al, 1994). 
No entanto, a crise ambiental atinge de diferentes formas diversos grupos de pessoas em diferentes regiões, potencializada por um modelo ocidental de desenvolvimento. Nos anos 60/70 do século XX, em um contexto pós-segunda Guerra Mundial, surgiu diversos movimentos de contestação política: o movimento estudantil em 1968 na França, o movimento dos direitos civis dos negros nos Estados Unidos, movimento social político de abertura democrática nos países latino-americanos, a segunda onda do movimento feminista e o movimento ambientalista, se constituíram e se fortaleceram. Nesses diferentes grupos, questionamentos e debates eram desencadeados, principalmente ao modelo de desenvolvimento concebido como um projeto ocidental moderno e que não trouxe a melhoria prometida. Ao contrário, tal projeto contribuiu para o crescimento da pobreza, para um aumento das desigualdades e para a degradação ambiental.

O movimento ecológico ou ambientalista constituídos principalmente por jovens e imersos num clima contracultural, articulavam influências do movimento estudantil de 1968, da nova esquerda, e do pacifismo em um ideário de mudança social e existencial de contestação à sociedade consumista e materialista, denunciando os riscos e impactos ambientais do modo de vidas das sociedades industriais modernas, tendo como horizonte utópico uma vida livre de normalizações e repressões sociais e em harmonia com a natureza (CARVALHO, 2012). O ideário contestador dos modos de vida das sociedades capitalista é um componente que unificou os diferentes sujeitos dos movimentos ecológicos (GUIMARÃES, 2008), mas apesar disto o movimento ecológico é múltiplo e variado, assim como a Educação Ambiental.

[...] queremos insistir que os movimentos ecológicos ao surgirem na esteira de um conjunto amplo de outros movimentos contestatórios inauguram, em relação aos discursos sobre a natureza de épocas anteriores, uma disseminada crítica global à sociedade industrial e aos estilos de vida dela derivados. Esse ideário, embora circulante pelos movimentos em seu conjunto, esteve longe de homogeneizá-los e circunscrevê-los a uma única direção. Os movimentos ecológicos aglutinaram um conjunto amplo de sujeitos com interesses e propósitos muito variados (GUIMARÃES, 2008, p.97)

Nesta trama podemos observar que o movimento ambientalista, feminista e outros movimentos sociais e políticos, emergem num contexto histórico e cultural. Assim, neste momento apresentamos alguns acontecimentos discursivos que dão visibilidade, condições de emergência para que a relação mulheres e natureza se constituam nos interstícios da Educação Ambiental, assim buscamos compreender alguns traçados históricos que fabricam discursos. $\mathrm{O}$ que nos interessa aqui é ver como a relação mulheres e natureza vem sendo amarrada a 
partir de diferentes conferências internacionais e atrelado ao campo de saber da Educação Ambiental, dando maior visibilidade para as mulheres convocando-as à proteção ambiental a nível global. Ao analisar os programas globais das Nações Unidas para o Desenvolvimento PNUD e União Internacional de Conservação da Natureza - UICN, conforme pesquisa realizada por Ávila, Ribeiro e Henning (2016), destaca-se a operação do gênero como dispositivo que, articulado aos dispositivos de Sustentabilidade e da Educação Ambiental, procura gerir a população para se alcançar o desenvolvimento sustentável. Nesta agenda global, o gênero vem enunciando e constituindo as mulheres na gestão do planeta para um melhor desenvolvimento no século XXI.

Isabel Carvalho (2012) nos provoca a repensar nosso olhar sobre as relações entre a sociedade e a natureza, isso significa "desnaturalizar" os modos de ver que tínhamos como óbvios, questionando conceitos já estabilizados em muitos campos da experiência humana. Através da nossa experiência histórica podemos reinventar novas maneiras de ser e estar no mundo. Através dessas experiências, as concepções de mundo e sua natureza são, muitas vezes, formas europeias de se ver a realidade, pois sabemos que a Europa dos séculos XV e XVI foi condição indispensável para que vários lugares e sociedades fossem integrados em um espaço mundial, através das navegações e rotas de comércio, com a expansão do capitalismo (CARVALHO, 1991).

Com o auxílio dos fundamentos da Educação Ambiental, podemos examinar a crise ambiental que se instala, ao tensionar nossas heranças modernas. Questionar as verdades e certezas que nos fazem se relacionar com a natureza de uma forma e não de outra, pensar nos tributos da ciência moderna em nossos modos de existir e conviver com a natureza. É a partir de Copérnico, Bacon, Descartes, Newton entre outros, que o Pensamento Moderno instaura modelos de técnica e ciência, formas de descrever e de dominar a natureza na atualidade.

A crise ambiental gerada e potencializada pela cultura ocidental, hoje dominante enquanto modelo cultural consolidado no planeta, as formas de nos relacionarmos com o mundo se estabelecem através do paradigma científico. Atrelado a este discurso científico, a Organização das Nações Unidas (ONU) realizou a Primeira Conferência das Nações Unidas sobre o Meio Ambiente Humano, em Estocolmo (Suécia), em junho de 1972, como consequência da reunião do Clube de Roma, realizada em 1968, que reuniu cientistas e empresários dos países industrializados. Estes cientistas publicaram o livro "Limites do Crescimento", no qual "deixaram clara a necessidade urgente de se buscar meios para a conservação dos recursos naturais e controlar o crescimento da população, além de se investir numa mudança radical na mentalidade de consumo e de procriação" (REIGOTA, 2014, p.22). 
Nesta conferência, as relações humanas com a natureza é pautada pelo paradigma científico em que posiciona o homem como indivíduo humano, como centro, protagonista tanto na destruição do planeta quanto na solução científica dos problemas ambientais, em uma visão antropocêntrica, ele é obra e criador do ambiente:

\begin{abstract}
O homem é ao mesmo tempo obra e construtor do meio ambiente que o cerca, o qual lhe dá sustento material e lhe oferece oportunidade para desenvolver-se intelectual, moral, social e espiritualmente. Em larga e tortuosa evolução da raça humana neste planeta chegou-se a uma etapa em que, graças à rápida aceleração da ciência e da tecnologia, o homem adquiriu o poder de transformar, de inúmeras maneiras e em uma escala sem precedentes, tudo que o cerca. Os dois aspectos do meio ambiente humano, o natural e o artificial, são essenciais para o bem-estar do homem e para o gozo dos direitos humanos fundamentais, inclusive o direito à vida mesma (CONFERÊNCIA, 1972).
\end{abstract}

As formas de ver a natureza e suas relações pautada pela racionalidade científica se constitui no dualismo do ambiente humano natural e artificial, segundo Isabel Carvalho (2012, p.116), "no método científico, a separação entre sujeito e objeto desdobrou-se em outras polaridades excludentes: natureza/cultura, corpo/mente, sujeito/objeto, razão/emoção". Para Garcia (1992) a dicotomia natureza/cultura não é universal e não há uniformidade no significado de natureza, cultura, masculino, feminino; portanto os significados e noções diferem entre homens e mulheres, assim como entre os homens, e entre as mulheres. Pode se constituir uma estratégia fértil para o pensamento ao desconstruir dicotomias (masculino/feminino, cultura/natureza, produção/reprodução, público-privado), problematizando os polos e evidenciando que cada polo não é uno, mas plural. Nas relações sociais, atravessadas por diferentes discursos, símbolos, representações e práticas, os sujeitos vão se construindo como masculinos e femininos, arranjando e desarranjando seus lugares sociais, suas disposições, suas formas de ser e estar no mundo (LOURO, 2014).

A maneira de ver o mundo, as leituras de natureza são marcadas por essa tradição do pensamento ocidental, portanto para pensar e problematizar como a relação mulheres e natureza vão se constituindo na Educação Ambiental na atualidade, se faz necessário pinçar alguns acontecimentos da história. Nesse texto, escolhemos alguns desses acontecimentos para compreender os processos de articulação que auxiliam na fabricação de um modo de relacionar mulher e natureza.

Comecemos por olhar a Conferência de Estocolmo, entendendo que esta conferência inclui definitivamente o tema ambiental na agenda multilateral e como prioridade das futuras negociações sobre o meio ambiente, além disso a partir deste evento cria-se o Programa das Nações Unidas para o Meio Ambiente - PNUMA. Entretanto, conforme Reigota (2014), pela 
primeira vez trouxe à tona a necessidade de educar a todos os cidadãos e cidadãs para a solução dos problemas ambientais, conforme princípio 19 da Declaração da Conferência das Nações Unidas sobre Meio Ambiente Humano:

\begin{abstract}
É indispensável um esforço para a educação em questões ambientais, dirigida tanto às gerações jovens como aos adultos e que preste a devida atenção ao setor da população menos privilegiado, para fundamentar as bases de uma opinião pública bem informada, e de uma conduta dos indivíduos, das empresas e das coletividades inspirada no sentido de sua responsabilidade sobre a proteção e melhoramento do meio ambiente em toda sua dimensão humana. É igualmente essencial que os meios de comunicação de massas evitem contribuir para a deterioração do meio ambiente humano e, ao contrário, difundam informação de caráter educativo sobre a necessidade de protegê-lo e melhorá-lo, a fim de que o homem possa desenvolver-se em todos os aspectos (CONFERÊNCIA, 1972) [grifo nosso].
\end{abstract}

Neste mesmo sentido, trazendo a importância para uma educação para as questões ambientais dirigida a todos os cidadãos, a Declaração da Conferência Intergovernamental sobre Educação Ambiental (Tbilisi) promove que "a Educação Ambiental deve abranger pessoas de todas as idades e de todos os níveis, no âmbito do ensino formal e não-formal" (CONFERÊNCIA, 1977). A partir desta Conferência, realizada através da parceria entre a UNESCO e o Programa de Meio Ambiente - PNUMA/ONU, que foi possível definir a Educação Ambiental, assim como seus objetivos, princípios e estratégias que até hoje são adotados em todo o mundo (CZAPSKI, 1998). A Educação Ambiental está inserida em uma trama muito maior que ela própria, e apresenta-se como possibilidade de olhar, perceber e compreender as relações de interdependências estabelecidas entre nós e a natureza, objetivo presente desde a primeira Conferência de Tbilisi (1977):

[...] lograr que os indivíduos e a coletividade compreendam a natureza complexa do meio ambiente natural e do meio ambiente criado pelo homem, resultante da integração de seus aspectos biológicos, físicos, sociais, econômicos e culturais, e adquiram os conhecimentos, os valores, os comportamentos e as habilidades práticas para participar responsável e eficazmente da prevenção e solução dos problemas ambientais, e da gestão da questão da qualidade do meio ambiente (CONFERÊNCIA, 1977) [grifo nosso].

A partir da Conferência de Estocolmo e de Tbilisi, a Educação Ambiental toma forma à nível global através das Nações Unidas, convocando a todos e todas na mudança de atitudes e comportamentos humanos em relação ao ambiente, tornando responsabilidade de toda a sociedade civil proteger o meio ambiente.

$\mathrm{Na}$ Conferência de Tbilisi, compreende-se que as relações humanas com a natureza são resultantes de uma integração de vários aspectos biológicos, físicos, sociais, econômicos e 
culturais, o que traz um grande desafio para o campo da Educação Ambiental. A participação de todos na resolução dos problemas ambientais globais presente nas categorias de objetivos na Conferência de Tbilisi (1977) torna-se como condições de possibilidade para que os movimentos ecológicos, sociais, inclusive movimentos feministas, se aproximem da Educação Ambiental.

Mas, foi a partir de 1992, que houve maior participação das mulheres nas conferências mundiais, especialmente na Eco-92, com contribuições para a Agenda 21 da ONU (capítulo 24), a Agenda 21 de Ação das Mulheres por um Planeta Saudável e pela Paz (Fórum Global, Eco-92, revisada em Johannesburgo, 2002) e a IV Conferência das Nações Unidas sobre Mulher, Desenvolvimento e Paz (Pequim, 1995), assim como na Rio+20 a Declaração do Território Global das Mulheres (VIEZZER, 2013). Esses instrumentos colaboraram no sentido de provocar a mobilização para a reflexão e construção de atitudes de mulheres e homens em relação à crise ambiental, incorporando o Gênero nas decisões relacionadas com o ambiente internacional, nacional e local (BRAIDOTTI et al., 1994).

A Conferência das Nações Unidas sobre Desenvolvimento e Meio Ambiente, realizada no Rio de Janeiro, em 1992, a ECO-92, teve como resultado dessa mobilização a Plataforma de Ação do Desenvolvimento Sustentável - Agenda 21 amplamente adotada pelos chefes de Estado, e mais especificamente o capítulo 24 que reúne um conjunto de recomendações, mecanismos e metas para integrar as mulheres e a questão de gênero em todos os níveis de governo e nas ações da Organização das Nações Unidas (CASTRO; ABRAMOVAY, 2005). Conforme o capítulo 24, intitulado "Ação Mundial pela Mulher, com vistas a um Desenvolvimento Sustentável e Equitativo" tem como base para a ação:

24.1. A comunidade internacional endossou vários planos de ação e convenções para a integração plena, eqüitativa e benéfica da mulher em todas as atividades relativas ao desenvolvimento, em particular, as Estratégias Prospectivas de Nairóbi para o Progresso da Mulher1/, que enfatizam a participação da mulher no manejo nacional $e$ internacional dos ecossistemas e no controle da degradação ambiental (...) (CONFERÊNCIA, 1992) [grifo nosso].

Neste capítulo da Agenda 21, as mulheres são fundamentais no manejo e no controle de degradação ambiental, numa estrita relação mulheres e natureza. Não é de hoje que as mulheres são relacionadas às questões que envolvem a natureza em uma relação de proximidade. Se atentarmos para a literatura ecofeminista, por exemplo, teremos algumas discussões sobre a relação de contribuição das mulheres com as questões ambientais. $\mathrm{Na}$ mitologia grega uma das primeiras representações divinas criadas pelos seres humanos foi a 
figura da Deusa, Gaia, a mãe terra. Deusas da natureza como ninfas - das florestas, das águas, das flores, da terra -, para citar algumas, representam uma relação próxima das mulheres com a natureza. Assim como Pachamama na cosmovisão andina. Nas mitologias Vikings e Celtas, bem como a literatura Wicca também podemos perceber uma relação próxima e que cultuavam a natureza (ANGELIN, 2014). Assim, a proximidade das mulheres com os elementos, recursos e manejos com a natureza é histórica e cultural. Como foco de investimentos para as questões ambientais tomamos o movimento das mulheres na ECO-92 como condições de possibilidade para emergência da relação mulheres e natureza nos interstícios da Educação Ambiental.

Paralelo à Conferência da ONU sobre Desenvolvimento e Meio Ambiente, no Rio de Janeiro, em 1992, ocorreu o Fórum Global que segundo Carvalho (2012) foi o evento não governamental mais importante para o avanço da Educação Ambiental, nessa ocasião as Organizações Não Governamentais (ONGs) e os movimentos sociais de todo o mundo formularam o Tratado de Educação Ambiental para Sociedades Sustentáveis. O Fórum Global abrigou diversas tendas com diferentes enfoques, entre elas o Planeta Fêmea, o acontecimento das mulheres dentro do Fórum Global. No Planeta Fêmea, organizado pela Coalizão de Mulheres Brasileiras, mulheres de diferentes nacionalidades discutiram os problemas enfrentados e vividos no planeta e formularam sua própria plataforma, a Agenda 21 de Ação das Mulheres, no qual trataram de temas como globalização, militarismo, governança, pobreza, direito da terra, segurança alimentar, direito das mulheres, direitos reprodutivos, ciência, tecnologia e educação, incluindo recomendações como novas formas de educação, preservação de recursos naturais e participação no planejamento de uma economia sustentável (CASTRO; ABRAMOVAY, 2005). Como relembra Oliveira (1992, p.142) sobre "Memórias do Planeta Fêmea":

\footnotetext{
A presença das mulheres na Eco 92 teve antes de mais nada uma função poética de invenção sideral. No sentido mais nobre da poesia, o de "manter sempre teso o arco da promessa". Foi por isso mesmo uma função política por excelência, a de recolocar o Sentido na linha do horizonte, linha que recua sempre, mas que nos faz desejar, linha que espelha todo movimento. Espelho do movimento, do nosso, Movimento de Mulheres.
}

A mobilização das mulheres na ECO-92 obteve alguns resultados: abriu espaço para a sua participação em todas as conferências da ONU, assim como o documento Agenda 21 das Mulheres por um Planeta Saudável balizou a intervenção do movimento feminista nas conferências que ocorreram nas próximas décadas; e consolidou uma visão de que o 
feminismo e ecologia estavam intrinsecamente ligados, uma vez que ambos propunham profundas mudanças na ordem natural, baseada na justiça social (CASTRO; ABRAMOVAY, 2005).

Mas foi a partir IV Conferência das Nações Unidas sobre a Mulher (Pequim, 1995) promovendo os objetivos de igualdade de gênero, desenvolvimento e paz para todas as mulheres do mundo. Conforme a Declaração da IV Conferência das Nações Unidas sobre Mulher, Desenvolvimento e Paz se faz necessário um desenvolvimento social equitativo que reconheça que dar aos pobres, em particular às mulheres que vivem na pobreza, a possiblidade de utilizar os recursos ambientais de maneira sustentável (Item 36, CONFERÊNCIA, 1995). Assim justificamos a escolha deste evento internacional como um acontecimento discursivo, um marco histórico que reconhece que para criar um novo paradigma de desenvolvimento é fundamental que se integre a preservação ambiental com a justiça e igualdade de gênero. Segundo a Plataforma de Ação da IV Conferência das Nações Unidas sobre Mulher, Desenvolvimento e Paz, quanto aos objetivos estratégicos e medidas, no item "A Mulher e o Meio Ambiente" que se baseia no capítulo 24 da Agenda 21 visto anteriormente:

\footnotetext{
248. Mediante a gestão e o uso dos recursos naturais, as mulheres dão sustentação à família e à comunidade. Como consumidoras, produtoras, educadoras e responsáveis pelo cuidado de suas famílias, as mulheres desempenham importante papel na promoção do desenvolvimento sustentável, pela sua preocupação com a qualidade e a sustentabilidade da vida para as gerações atuais e futuras. Os governos têm manifestado sua intenção de estabelecer um novo paradigma de desenvolvimento, capaz de integrar a preservação do meio ambiente com a justiça e a igualdade de gênero, dentro de uma mesma geração e entre distintas gerações, como está expresso no capítulo 24 da Agenda 21 (CONFERÊNCIA, 1995, p.236).
}

Na seara da Educação Ambiental, o conceito de Gênero traz visibilidade para as mulheres, posicionando-as como protagonistas para um futuro sustentável do Planeta, observamos que na Eco-92 aparece as questões das mulheres com o meio ambiente e depois as próximas conferências começam a abordar gênero e desenvolvimento sustentável. Além disso, o Tratado de Educação Ambiental para Sociedades Sustentáveis e Responsabilidade Global, fruto dos debates, disputas e lutas que perpassam as conferências ambientais apontam para a dimensão de gênero como parte do processo educativo para uma sociedade sustentável. Assim, podemos notar as rachaduras que o gênero provocou na Educação Ambiental, que considerava o homem como representação da humanidade. Nos princípios do tratado é destacado a corresponsabilidade dos gêneros na produção, reprodução e manutenção da vida. Além disso, enfatiza que a Educação Ambiental deve promover o diálogo e a cooperação a 
fim de criar novos modos de vida sem distinção de gênero e intersecções de raça, idade, classe, religião, etc.

\section{Algumas considerações}

Num contexto histórico e cultural, em uma construção mútua dos movimentos ambientalistas e feministas, em diversas instâncias governamentais e não governamentais, se tornou em posição de destaque a relação das mulheres com a natureza na seara da Educação Ambiental. Se num dado momento histórico temos o homem como centro da resolução dos problemas ambientais pautado pela racionalidade científica, agora nesta nova trama, em um momento de crise mundial convoca-se as mulheres para proteção e cuidado do planeta.

O que nos interessa aqui, não é destacar o certo e o errado nas nossas relações com a natureza, mas evidenciar as construções históricas e culturais que constituem esta relação. E principalmente mostrar o quanto estes modos de pensar, valorizar e se relacionar com a natureza vêm se constituindo e se modificando pela história e cultura, com o intuito de problematizarmos e (re)inventarmos novos modos de nos relacionar com a natureza na atualidade nos interstícios da Educação Ambiental.

\section{Referências}

ANGELIN, R. Mulheres, ecofeminismo e desenvolvimento sustentável diante das perspectivas de redistribuição e reconhecimento de gênero. Itajaí: Estamos preparados? Rev Eletr. Direito e Política. UNIVALI, v.9, n 3, p. 1569-1597, 2014.

ÁVILA, D. A. RIBEIRO, P.R.C. E HENNING, P.C. "O Gênero é fundamental para o desenvolvimento sustentável": reflexões sobre a operação de dispositivos em programas globais e seus efeitos para a Educação Ambiental. Rio Grande: REMEA, Ed. Especial, p.95119, julho/2016. Disponível em: https://www.seer.furg.br/remea/article/viewFile/5962/3685 Acesso em: 05 de setembro de 2016.

BRAIDOTTI, Rosi; CHARKIEWICZ, Ewa; HAUSLER, Sabine; WIERINGA, Saskia. Mulher, ambiente e desenvolvimento sustentável. Para uma síntese teórica. São Paulo: Instituto Piaget, 1994

CARVALHO, I.C. de M. Educação ambiental: a formação do sujeito ecológico. São Paulo: Cortez, 6aed., 256p., 2012.

CARVALHO, M. O que é Natureza? São Paulo: Editora Brasiliense, 1991.

CASTRO, M.G.; ABRAMOPVAY, M. Gênero e Meio Ambiente. São Paulo: Cortez Editora, $2^{\circ}$ ed., 144p., 2005.

CZAPSKI, S. A implantação da Educação Ambiental no Brasil. Brasília: MEC, 166p.,1998. 


\section{CONFERÊNCIA DAS NAÇÕES UNIDAS SOBRE MEIO AMBIENTE HUMANO.}

DECLARAÇÃO. Estocolmo, 1972. Disponível em:

www.mma.gov.br/estruturas/agenda21/_arquivos/estocolmo.doc Acesso em: 18 de setembro de 2017.

\section{CONFERÊNCIA INTERGOVERNAMENTAL DE EDUCAÇÃO AMBIENTAL.}

DECLARAÇÃO. Tbilisi, 1977. Disponível em:

www.mma.gov.br/port/sdi/ea/deds/pdfs/decltbilisi.pdf Acesso em: 18 de setembro de 2017.

\section{CONFERÊNCIA INTERGOVERNAMENTAL DE EDUCAÇÃO AMBIENTAL.} RECOMENDAÇÕES. Tbilisi, 1977.Disponível em:

www.fzb.rs.gov.br/upload/20130508155354tbilisi.pdf Acesso em: 18 de setembro de 2017.

\section{CONFERÊNCIA DAS NAÇÕES UNIDAS SOBRE DESENVOLVIMENTO E MEIO}

AMBIENTE. PLATAFORMA DE AÇÃO, CAPÍTULO 24. Rio de Janeiro, 1992. Disponível em: www.mma.gov.br/estruturas/agenda21/_arquivos/cap24.doc Acesso em: 18 de setembro de 2017.

CONFERÊNCIA DAS NAÇÕES UNIDAS SOBRE MULHER, DESENVOLVIMENTO E PAZ, IV. DECLARAÇÃO E PLATAFORMA DE AÇÃO. Pequim, 1995. Disponível em: http://www.un.org/womenwatch/daw/beijing/pdf/BDPfA\%20S.pdf Acesso em: 18 de setembro de 2017.

FOUCAULT, M. A ordem do discurso: aula inaugural no Collège de France, pronunciada em 2 de dezembro de 1970. São Paulo: Edições Loyola, 24ºd. 74p., 2014.

GARCIA. S.M. Desfazendo os vínculos naturais entre gênero e meio ambiente. Revista de Estudos Feministas, Rio de Janeiro, v.0,n.0, p.163-68,1992. Disponível em:

http://www.redalyc.org/pdf/381/38126508015.pdf Acesso em: 05 de setembro de 2016.

GUIMARÃES, L. B. A importância da história e da cultura nas leituras da natureza. InterAção: Rev. Fac. Educ. UFG, v. 33, n.1, p. 87-101, jan./jun. 2008. Disponível em:

https://revistas.ufg.br/interacao/article/viewFile/4244/4174 Acesso em: 05 de setembro de 2016.

HENNING, Paula Corrêa. Provocações para este tempo... a Educação Ambiental nos atravessamentos midiáticos. In.: PREVE, Ana Maria H.; GUIMARÃES, Leandro B.; BARCELOS, Valdo e LOCATELLI, Julia S. (org). Ecologias Inventivas: conversas sobre educação. Santa Cruz do Sul: EDUNISC, 2012. P. 241-253.

LOURO, Guacira Lopes. Gênero, sexualidade e educação: uma perspectiva pósestruturalista. Petrópolis/RJ: Vozes, 2014.

MEYER, D.E. Teorias e Políticas de Gêneros: fragmentos históricos e desafios atuais. Brasília (DF): Rev. Bras. Enferm. , nº 57, v.1, p.13-18, jan-fev. 2004.

OLIVEIRA, R.D. de. Memórias do Planeta Fêmea. Estudos Feministas, nº, 1992, p. 131142. 
REIGOTA, Marcos. O que é Educação Ambiental? São Paulo: Brasiliense, 2014.

VIEZZER, M.L. Gênero. In: FERRARO JÚNIOR, L.A. (Org.). Encontros e Caminhos: Formação de Educadoras (es) Ambientais e Coletivos Educadores. V. 3. Brasília: MMA/DEA, p.171-184, 2013. 